\title{
Monoclonal Antibody-Based Enzyme Immunoassay for Epidemiological Studies of Asymptomatic Dengue Infection
}

\author{
Supawat Chatchen, Kriengsak Limkittikul, Pimolpachr Sriburin, Arunee Sabchareon, \\ Chukiat Sirivichayakul \\ Department of Tropical Pediatrics, Faculty of Tropical Medicine, Mahidol University, Bangkok, Thailand \\ Email: supawat.cht@mahidol.ac.th
}

Received 10 August 2016; accepted 10 September 2016; published 13 September 2016

Copyright (C) 2016 by authors and Scientific Research Publishing Inc.

This work is licensed under the Creative Commons Attribution International License (CC BY).

http://creativecommons.org/licenses/by/4.0/

(c) (i) Open Access

\begin{abstract}
Dengue virus (DENV) is the world most prevalent mosquito-transmitted virus. The incidence of dengue infection has been increasing and most of the infected people are asymptomatic or have non specific febrile illness. Laboratory test is essential to confirm dengue infection in epidemiological studies. We developed an indirect ELISA test based on monoclonal immunoglobulin against all four DENV serotypes and evaluated the test for the diagnosis of asymptomatic dengue infection in paired annual serum samples. The indirect ELISA was found to have a sensitivity $87.5 \%$ and specificity $78.3 \%$ at optimized cut off. The results from indirect ELISA demonstrate an incidence of asymptomatic dengue infection from children aged 4 - 11 years in Ratchaburi province, Thailand (2006-2009). These findings indicate that the indirect ELISA is suitable for serodiagnosis and seroepidemiological studies of asymptomatic dengue infection.
\end{abstract}

\section{Keywords}

PRNT, Indirect ELISA, Asymptomatic, Dengue Infection, Ratchaburi Province Thailand

\section{Introduction}

Dengue virus (DENV) is a major arbovirus responsible for infection in an estimated 2.5 - 3.0 billion people at risk worldwide. DENV consists of 4 serotypes of antigenically distinct single stranded RNA viruses (D1 - D4) in the genus Flavivirus, family Flaviviridae. Dengue infection may result in asymptomatic infection, dengue fever (DF), dengue hemorrhagic fever (DHF) or dengue shock syndrome (DSS) [1]-[4]. The pathogenesis of disease severity is not completely understood [5]-[7]. Infection with one serotype can cause life-long immunity

How to cite this paper: Chatchen, S., Limkittikul, K., Sriburin, P., Sabchareon, A. and Sirivichayakul, C. (2016) Monoclonal Antibody-Based Enzyme Immunoassay for Epidemiological Studies of Asymptomatic Dengue Infection. Advances in Infectious Diseases, 6, 113-119. http://dx.doi.org/10.4236/aid.2016.63015 
against the original serotype but transient cross protection to the other serotypes.

Asymptomatic infection is the most common clinical syndrome of dengue and may have a role in dengue transmission [8]-[12]. Epidemiological studies on asymptomatic dengue infection are essential and the incidence of asymptomatic dengue infection also reflects the quality of dengue control. In addition, patterns of pre-existing immunity between asymptomatic and symptomatic dengue infection may also provide insight on the pathogenesis of dengue disease.

The detection of antibodies by serological methods is very useful for dengue diagnosis. Serological tests usually need two blood samples to detect rising antibody levels. Three serological tests have been used for detecting asymptomatic dengue infection: hemagglutination-inhibition test (HAI), enzyme-linked immunosorbent assay (ELISA) and plaque reduction neutralization test (PRNT) [13]-[17]. PRNT is the only test that measures the biological parameter of in vitro virus neutralization, and therefore is the most virus specific serological test among flaviviruses. PRNT is regarded as the "gold standard" serological method for the diagnosis of DENV [18]-[21]. However, PRNT has some practical disadvantages because it is technically demanding, labor intensive and time consuming. ELISA is rapid, simple to perform, relatively inexpensive and easier to standardize.

We developed an indirect ELISA test based on monoclonal immunoglobulin against all four serotypes of DENV to diagnosis asymptomatic dengue infection in paired annual serum samples in a dengue endemic area in Thailand comparing to PRNT.

\section{Materials and Methods}

\subsection{Indirect Enzyme-Linked Immunosorbent Assay}

For the indirect ELISA, 96-well ELISA plates were filled with $100 \mu \mathrm{l} /$ well of a diluted dengue monoclonal antibody $2 \mathrm{H} 2$ [22] 1:50 in $0.018 \mathrm{M}$ carbonate buffer. After overnight incubation at $4{ }^{\circ} \mathrm{C}$, the plates were washed 6 times with $300 \mu \mathrm{l} /$ well of phosphate buffer solution containing 1\% between 20 (PBS-T) and blocked with 5\% skim milk in PBS-T for 1 hour at $37^{\circ} \mathrm{C}$. After washing procedures, the plates were filled with $50 \mu \mathrm{l} /$ well of an equal mixture of DENV1-4(C6/36) antigen. After one hour incubation at $37^{\circ} \mathrm{C}$, the plates were washed as previously described.

The serum samples and controls were diluted at 1:400 with 5\% skim milk in PBS-T. Fifty microliters per well of diluted serum were added in duplicate, and the plates were incubated at $37^{\circ} \mathrm{C}$ for 1 hour. After washing again, the plates were filled with $50 \mu \mathrm{l} /$ well of a goat-anti-human IgG antibody conjugated to horse radish peroxidase (KPL Inc., Gaithersburg, MD), diluted at 1:5000 in PBS-T with 5\% skim milk. After incubation at $37^{\circ} \mathrm{C}$ for 60 min, the plates were washed 6 times and the substrate SureBlue ${ }^{\mathrm{tm}}$ TMP (KPL Inc., Gaithersburg, MD) was added. After incubation at room temperature for $30 \mathrm{~min}$, the reaction was terminated by the addition of $50 \mu \mathrm{l}$ of 0.2 M sulfuric acid to each well and read at $450 \mathrm{~nm}$ using ELISA plate reader.

\subsection{Plaque Reduction Neutralization Test}

The serum samples were tested for specific antibodies against DENV1-4 (kindly provided by Armed Forces Research Institute of Medical Sciences) using a 50\% plaque reduction criteria as described previously [19]. Briefly, a monolayer of LLC-MK2 cells in M199 growth media was cultivated on the 12-well plates. The serum samples were inactivated $\left(56^{\circ} \mathrm{C}\right.$ for $\left.30 \mathrm{~min}\right)$ and serially diluted to 1:10, 1:40. 1:160, 1:640 and 1:2560 by MEM diluent media. Each DENV serotype was then separately added into diluted serum and serum-virus mixtures were incubated at $35^{\circ} \mathrm{C}$ for $60 \mathrm{~min}$. The mixtures were then inoculated onto monolayer LLC-MK2 cells in 12-well plates. After four days of incubation at $35^{\circ} \mathrm{C}$ in $5 \% \mathrm{CO}_{2}$, neutral red was used for straining the inoculated cells. Each serum was tested in duplicate, and the plaque-forming unit (pfu) was recorded as the average of the number obtained in each of the two cultures. PRNT50 was calculated by probit model with the SPSS program. The PRNT50 end point titers were expressed as the reciprocal of the last serum dilution.

\subsection{Serum Samples}

In this study, serum samples were from the cohort epidemiology study of dengue infection in school aged children in Ratchaburi province, Thailand during 2006 to 2009. The cohort recruited approximately 3000 primary school children. There were 333 RT-PCR proved dengue episodes out of 5842 febrile episodes [23]. All serum samples were stored at $-80^{\circ} \mathrm{C}$ until used. Twenty two paired annual sera from children who had symptomatic 
RT-PCR proven dengue infection were randomly selected from the whole cohort and tested for both PRNT50 and indirect ELISA (DENV1 $=9$ cases, DENV2 $=7$ cases, DENV3 $=6$ cases). For children who had no history of dengue infection, indirect ELISA test was performed on totally 5,513 paired serum samples. Forty paired serum samples from those who had a rise in ELISA titer (ratio > 1.5) and 32 paired serum samples from those who had no a rise in ELISA titer (totally 72 paired sera) were randomly selected to test for PRNT50. Rising ratio was calculated by fold of rised titer between annual serum samples, for example, ratio 1.5 means this year titer increases 1.5 times than the previous year titer.

All data were handled confidentially and anonymously. This study was reviewed and approved by the ethics committee of the faculty of tropical medicine, Mahidol University (protocol TMEC 14-074).

\subsection{Data Analysis}

Statistical analysis was performed with SPSS version 18.0 (SPSS, Inc., Chicago, IL). Data were analyzed by unpaired t-test to determine the difference between groups. P-value $<0.05$ is considered as statistical significance.

\section{Results}

\subsection{Cut-Off Criterion for the Diagnosis of Dengue Infection by PRNT50 in Paired Annual Sera}

To evaluate the cut off criterion for PRNT50, 22 paired annual serum samples of RT-PCR proven symptomatic dengue infection cases and 72 paired annual serum samples of children with no history of symptomatic infection were tested by PRNT50. It was found that all RT-PCR proven symptomatic dengue infection cases had at least 16 folds rising to at least one serotype (Figure 1 and Table 1). A cut-off criterion for the diagnosis of dengue infection in paired annual sera is therefore $\geq 16$ folds rising. While $36.1 \%$ of children with no history of symptomatic dengue infection had at least 16 folds rising in PRNT50 titers.

\subsection{Cut-Off Criterion for the Diagnosis of Asymptomatic Dengue Infection by ELISA in Paired Annual Sera}

To evaluate the cut off criterion for indirect-ELISA, the same set of samples was tested by indirect-ELISA. A rising ratio in the optical density (OD) at $450 \mathrm{~nm}$ of the intervening year was calculated. Ratios in ELISA OD of both groups were shown in Figure 2. A cut-off criterion for diagnosis of dengue infection in paired annual sera is therefore the ratio $\geq 2.0$.

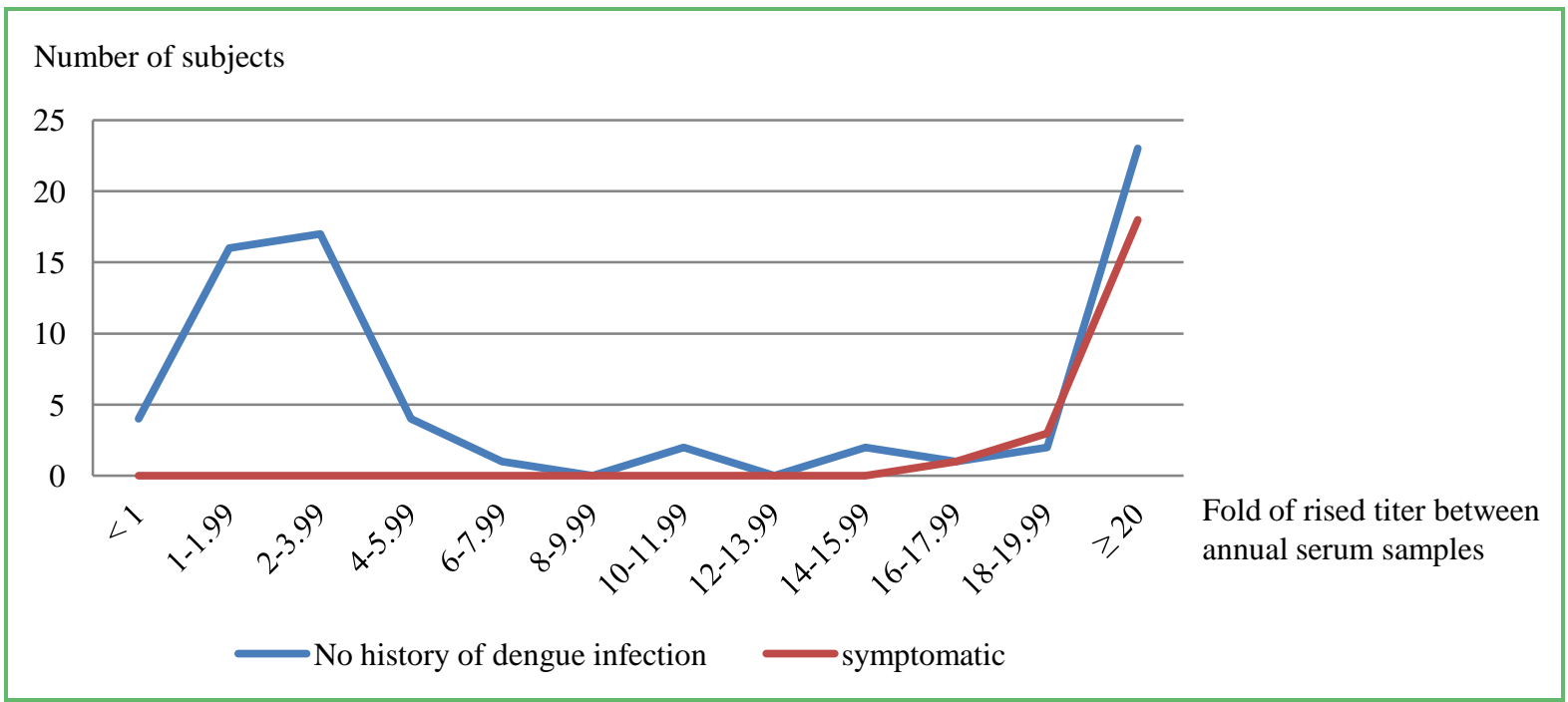

Figure 1. Number of subjects who had a rise in PRNT titer comparing between the subjects who had symptomatic dengue infection and who had no history of dengue infection. 
Table 1. Comparison of PRNT50 and indirect ELISA in symptomatic dengue patients and subjects who had no history of dengue infection.

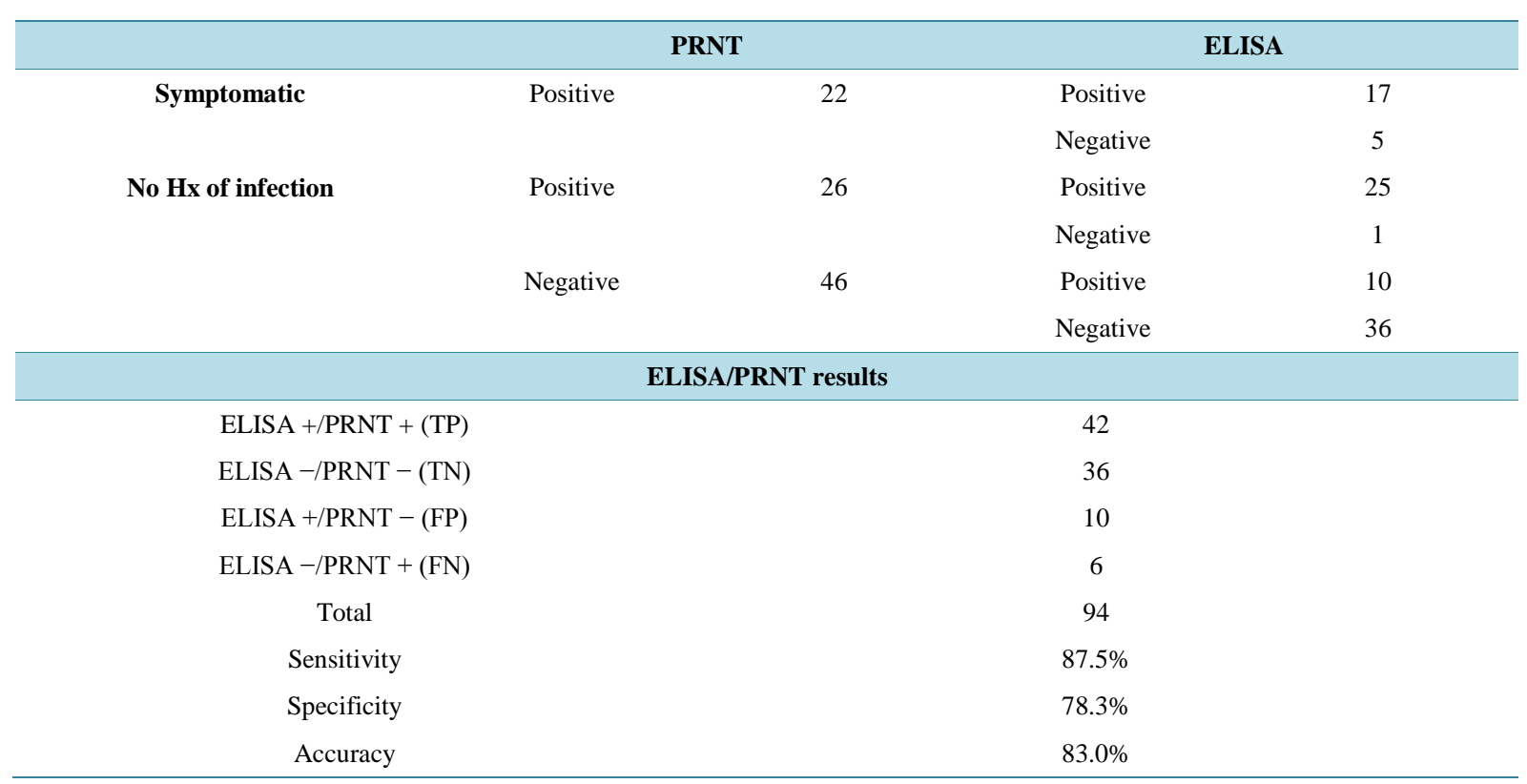

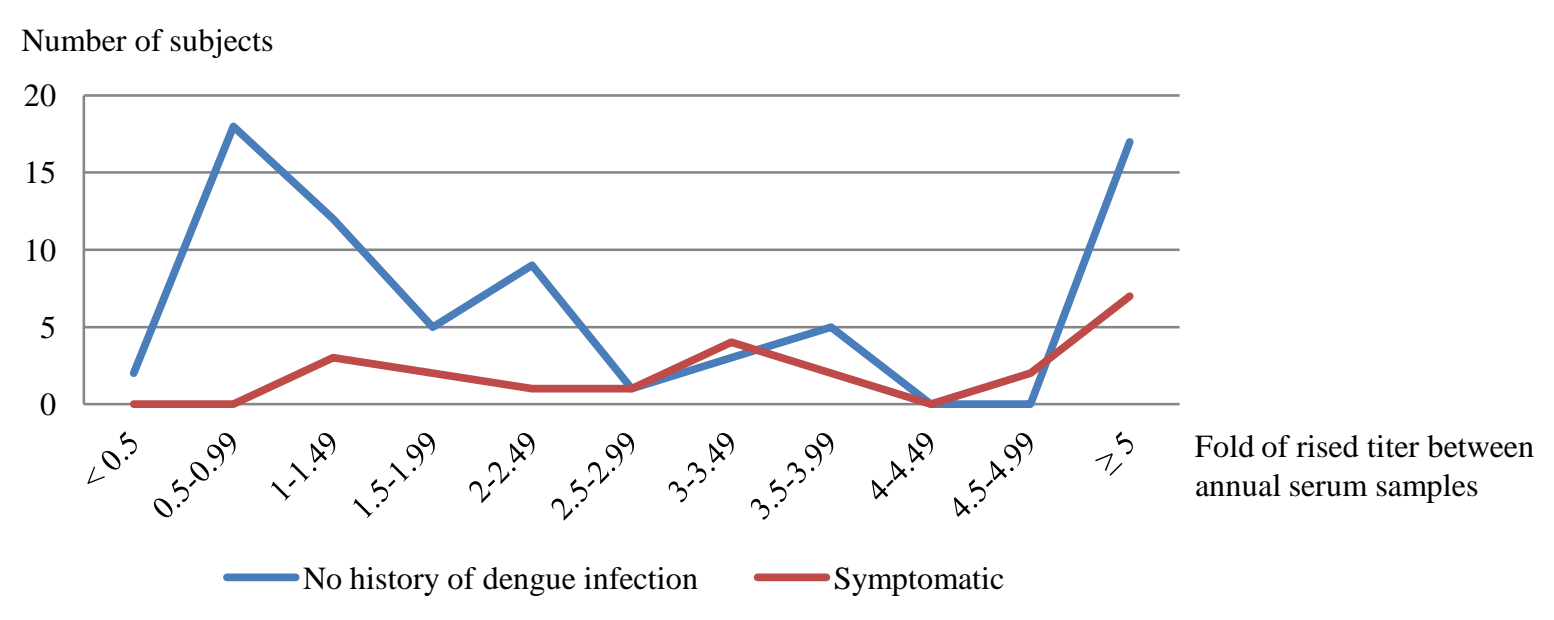

Figure 2. Number of subjects who had a rise in ELISA titer comparing between the subjects who had symptomatic dengue infection and who had no history of dengue infection.

The results summarized in Table 1 indicated that $51.4 \%$ of children with no history of symptomatic infection were non dengue infection and $48.6 \%$ were asymptomatic dengue infection.

\subsection{Correlation between Indirect ELISA and PRNT50}

Figure 3 shows the Spearman's correlation between the rising ratio of PRNT50 and indirect ELISA in all 94 annual serum samples. Their $\mathrm{r}$ was $0.736(p<0.001)$ indicating that there is a significant correlation. Using PRNT50 as the gold standard, the accuracy of indirect ELISA was 83.0\% (Table 1).

\subsection{Incidence of Asymptomatic Dengue Infection}

To estimate the incidence of asymptomatic dengue infection, total annual serum samples collected from children aged 4 - 11 years in Ratchaburi province, Thailand (2006-2009) were tested using the indirect-ELISA. A rising 


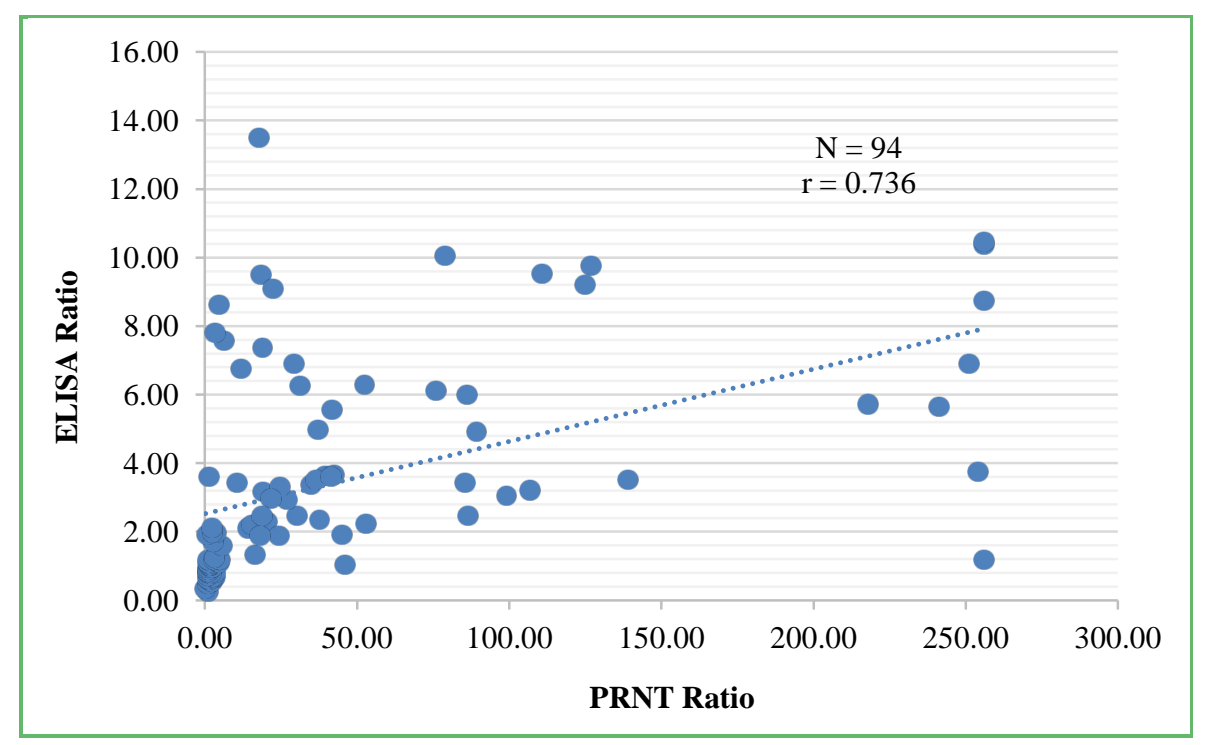

Figure 3. Spearman's correlation between rising ratios of indirect ELISA and PRNT50 $(\mathrm{P}<$ 0.001).

ratio in the $\mathrm{OD}$ at $450 \mathrm{~nm}$ of the intervening year was analyzed. A seroconversion was interpreted using ratio 2.0 or higher. The results showed that $8.9 \%(489 / 5,513)$ of the population were asymptomatic dengue infection. In this population, symptomatic dengue infection rate was 3.6\% during 2006 to 2009. Therefore, symptomatic: asymptomatic dengue infection (S:A) ratio in the study area of Ratchaburi province, Thailand in that period was approximately $1: 2.5$.

\section{Discussion}

After dengue infection, there will be IgM and IgG antibody responses and IgG level may persist for more than one year. The detection of rising in IgG level is therefore able to detect recent dengue infection, both symptomatic and asymptomatic. The appropriate methods for detecting asymptomatic dengue infection depend on objectives, budgets and the feasibility. Although PRNT has been used for over 30 years as the most sensitive and specific method to detect dengue infection but it still has limitations including high cost, time consuming and variation among tests. Several dengue immunoenzymatic assays have been developed with different formats as alternatives to PRNT. Using ELISA is an attractive possibility as an alternative test for PRNT with comparable performance and better feasibility in the future [24].

The diagnostic criteria for recent dengue infection using paired annual serum sample may be different from the criteria used for acute dengue infection using acute and convalescent sera because the rise in IgG level may decline. We therefore evaluate the rise in PRNT50 and ELISA in 22 paired annual sera of patients with symptomatic RT-PCR proven dengue infection. It was shown that all of the symptomatic dengue subjects had a rise in PRNT50 titer $\geq 16$ folds to at least one serotype but the cut-off point was less clear for indirect ELISA. Five subjects had a rise in titer ranged from $1-1.99$ and 17 subjects had a rise in titer $\geq 2.0$. However, the performance of indirect ELISA was generally comparable to PRNT50 in both symptomatic dengue infection and in the children who had no history of dengue infection that may be either had no infection or had asymptomatic infection.

We also compared the different cut-off points of indirect ELISA to PRNT50. Using cut-off point at 1.5, the sensitivity and the specificity are $93.8 \%$ and $65.2 \%$ respectively. When using cut-off point at 1.9 , the sensitivity and the specificity are $93.8 \%$ and $73.9 \%$ respectively. For optimal specificity, cut-off point at 2.0 is selected and the sensitivity and specificity become $87.5 \%$ and $78.3 \%$ respectively.

The results reported herein indicate that our indirect-ELISA provides a feasible and quite accurate diagnosis for asymptomatic dengue infection. This indirect ELISA test can be applied in epidemiological studies of asymptomatic dengue infection and need only once a year blood samples which may be more acceptable in children than multiple blood samplings. 
According to the cohort epidemiological study of dengue infection from children aged 4 - 11 years in Ratchaburi province, Thailand (2007-2010), a considerable proportion of asymptomatic dengue infection was 8.9\% (489/5513). The incidence of symptomatic dengue infection in the study was 394 cases which can be classified to undifferentiated fever (UF) 210 cases, DF 142 cases and DHF 42 cases. Therefore, the ratio of symptomatic and asymptomatic (S:A) in the study area during 2007-2010 was 1:2.5. Study in Kamphaeng Phet province, Thailand (2004-2008) reported the symptomatic to inapparent (S:I) dengue illness ratio was 1:3 which was similar to our result [25]. Therefore, indirect ELISA test can be used for detecting asymptomatic dengue infection in epidemiological study which the comparable result as HAI test shown in Kamphaeng Phet study.

One limitation in this study is that most of the dengue infections in the study population are secondary infection [23]. As secondary infections result in anamnestic response with much higher IgG seroconversion than primary response, the cut-off point of 2.0 may be accurate only in the population with mainly secondary dengue infection. The cut-off point for the population with mainly primary dengue infection may be lower than 2.0. There is a need to further evaluate the applicability and cut-off value of indirect ELISA in these populations.

\section{Conclusion}

Indirect-ELISA is rapid and easy to perform, and has shown to be comparable to PRNT as serodiagnosis of asymptomatic dengue infection.

\section{Acknowledgements}

This study was supported by Mahidol University, Thailand.

\section{References}

[1] Monath, T.P. (1994) Dengue: The Risk to Developed and Developing Countries. Proceedings of the National Academy of Sciences of the United States of America, 91, 2395-400. http://dx.doi.org/10.1073/pnas.91.7.2395

[2] Kuno, G. (1995) Review of the Factors Modulating Dengue Transmission. Epidemiologic Reviews, 17, 321-335.

[3] Gubler, D.J. (2002) Epidemic Dengue/Dengue Hemorrhagic Fever as a Public Health, Social and Economic Problem in the $21^{\text {st }}$ Century. Trends Microbiology, 10, 100-103. http://dx.doi.org/10.1016/S0966-842X(01)02288-0

[4] Gubler, D.J. (2004) The Changing Epidemiology of Yellow Fever and Dengue, 1900 to 2003: Full Circle? Comparative Immunology Microbiology and Infectious Disease, 27, 319-330. http://dx.doi.org/10.1016/j.cimid.2004.03.013

[5] Rothman, A.L. and Ennis, F.A. (1999) Immunopathogenesis of Dengue Hemorrhagic Fever. Virology, 257, 1-6. http://dx.doi.org/10.1006/viro.1999.9656

[6] Watts, D.M., Porter, K.R., Putvatana, P., Vasquez, B., Calampa, C., Hayes, C.G. and Halstead, S.B. (1999) Failure of Secondary Infection with American Genotype Dengue 2 to Cause Dengue Haemorrhagic Fever. Lancet, 354, 14311434. http://dx.doi.org/10.1016/S0140-6736(99)04015-5

[7] Kochel, T.J., Watts, D.M., Halstead, S.B., Hayes, C.G., Espinoza, A., Felices, V., Caceda, R., Bautista, C.T., Montoya, Y., Douglas, S. and Russell, K.L. (2002) Effect of Dengue-1 Antibodies on American Dengue-2 Viral Infection and Dengue Haemorrhagic Fever. Lancet, 360, 310-312. http://dx.doi.org/10.1016/S0140-6736(02)09522-3

[8] Duong, V., Lambrechts, L., Paul, R.E., Ly, S., Lay, R.S., Long, K.C., Huy, R., Tarantola, A., Scott, T.W., Sakuntabhai, A. and Buchy, P. (2015) Asymptomatic Humans Transmit Dengue Virus to Mosquitoes. Proceedings of the National Academy of Sciences of the United States of America, 112, 14688-14693. http://dx.doi.org/10.1073/pnas.1508114112

[9] Tang, K.F. and Ooi, E.E. (2012) Diagnosis of Dengue: An Update. Expert Review of Anti-infective Therapy, 10, 895907. http://dx.doi.org/10.1586/eri.12.76

[10] Liu, L., Wen, K., Li, J., Hu, D., Huang, Y., Qiu, L., Cai, J. and Che, X. (2012) Comparison of Plaque- and EnzymeLinked Immunospot-Based Assays to Measure the Neutralizing Activities of Monoclonal Antibodies Specific to Domain III of Dengue Virus Envelope Protein. Clinical and Vaccine Immunology, 19, 73-78. http://dx.doi.org/10.1128/CVI.05388-11

[11] Sirivichayakul, C., Sabchareon, A., Limkittikul, K. and Yoksan, S. (2014) Plaque Reduction Neutralization Antibody Test Does Not Accurately Predict Protection against Dengue Infection in Ratchaburi Cohort, Thailand. Virology Journal, 11, 48. http://dx.doi.org/10.1186/1743-422X-11-48

[12] Graham, R.R., Juffrie, M., Tan, R., Hayes, C.G., Laksono, I., Ma’roef, C., Erlin, Sutaryo, Porter, K.R. and Halstead, S.B. (1999) A Prospective Seroepidemiologic Study on Dengue in Children Four to Nine Years of Age in Yogyakarta, Indonesia I. Studies in 1995-1996. American Journal of Tropical Medicine and Hygiene, 61, 412-419. 
[13] Roehrig, J.T., Hombach, J. and Barrett, A.D. (2008) Guidelines for Plaque-Reduction Neutralization Testing of Human Antibodies to Dengue Viruses. Viral Immunology, 21, 123-132. http://dx.doi.org/10.1089/vim.2008.0007

[14] Timiryasova, T.M., Bonaparte, M.I., Luo, P., Zedar, R., Hu, B.T. and Hildreth, S.W. (2013) Optimization and Validation of a Plaque Reduction Neutralization Test for the Detection of Neutralizing Antibodies to Four Serotypes of Dengue Virus Used in Support of Dengue Vaccine Development. American Journal of Tropical Medicine and Hygiene, 88, 962-970. http://dx.doi.org/10.4269/ajtmh.12-0461

[15] Rainwater-Lovett, K., Rodriguez-Barraquer, I., Cummings, D.A. and Lessler, J. (2012) Variation in Dengue Virus Plaque Reduction Neutralization Testing: Systematic Review and Pooled Analysis. BMC Infectious Diseases, 12, 233. http://dx.doi.org/10.1186/1471-2334-12-233

[16] Thomas, S.J., Nisalak, A., Anderson, K.B., Libraty, D.H., Kalayanarooj, S., Vaughn, D.W., Putnak, R., Gibbons, R.V., Jarman, R. and Endy, T.P. (2009) Dengue Plaque Reduction Neutralization Test (PRNT) in Primary and Secondary Dengue Virus Infections: How Alterations in Assay Conditions Impact Performance. American Journal of Tropical Medicine and Hygiene, 81, 825-833. http://dx.doi.org/10.4269/ajtmh.2009.08-0625

[17] Burke, D.S., Nisalak, A., Johnson, D.E. and Scott, R.M. (1988) A Prospective Study of Dengue Infections in Bangkok. American Journal of Tropical Medicine and Hygiene, 38, 172-180.

[18] Flipse, J. and Smit, J.M. (2015) The Complexity of a Dengue Vaccine: A Review of the Human Antibody Response. PLoS Neglected Tropical Diseases, 9, e0003749. http://dx.doi.org/10.1371/journal.pntd.0003749

[19] Russell, P.K., Nisalak, A., Sukhavachana, P. and Vivona, S. (1967) A Plaque Reduction Test for Dengue Virus Neutralizing Antibodies. Journal of Immunology, 99, 285-290.

[20] World Health Organization (2007) Guidelines for Plaque-Reduction Neutralization Testing of Human Antibodies to Dengue Viruses. http://apps.who.int/iris/bitstream/10665/69687/1/who ivb 07.07 eng.pdf

[21] Sang, C.T., Cuzzubbo, A.J. and Devine, P.L. (1998) Evaluation of a Commercial Capture Enzyme-Linked Immunosorbent Assay for Detection of Immunoglobulin M and G Antibodies Produced during Dengue Infection. Clinical and Diagnostic Laboratory Immunology, 5, 7-10.

[22] Setthapramote, C., Sasaki, T., Puiprom, O., Limkittikul, K., Pitaksajjakul, P., Pipattanaboon, C., Sasayama, M., Leuangwutiwong, P., Phumratanaprapin, W., Chamnachanan, S., Kusolsuk, T., Jittmittraphap, A., Asai, A., Arias, J.F., Hirai, I., Kuhara, M., Okuno, Y., Kurosu, T., Ramasoota, P. and Ikuta, K. (2012) Human Monoclonal Antibodies to Neutralize All Dengue Virus Serotypes Using Lymphocytes from Patients at Acute Phase of the Secondary Infection. Biochemical and Biophysical Research Communications, 423, 867-872. http://dx.doi.org/10.1016/j.bbrc.2012.06.057

[23] Sabchareon, A., Sirivichayakul, C., Limkittikul, K., Chanthavanich, P., Suvannadabba, S., Jiwariyavej, V., Dulyachai, W., Pengsaa, K., Margolis, H.S. and Letson, G.W. (2012) Dengue Infection in Children in Ratchaburi, Thailand: A Cohort Study. I. Epidemiology of Symptomatic Acute Dengue Infection in Children, 2006-2009. PLoS Neglected Tropical Diseases, 6, e1732.

[24] Rocha, E.S., Oliveira, J.G., Santos, J.R., Rodrigues, G.O., Figueiredo, L.B., Pessanha, J.E., Proietti, F.A., Fonseca, F.G., Bonjardim, C.A., Ferreira, P.C. and Kroon, E.G. (2013) Recombinant Envelope Protein-Based Enzyme Immunoassay for IgG Antibodies Is Comparable to Neutralization Tests for Epidemiological Studies of Dengue Infection. Journal of Virological Methods, 187, 114-120. http://dx.doi.org/10.1016/j.jviromet.2012.09.012

[25] Mammen, M.P., Pimgate, C., Koenraadt, C.J., Rothman, A.L., Aldstadt, J., Nisalak, A., Jarman, R.G., Jones, J.W., Srikiatkhachorn, A., Ypil-Butac, C.A., Getis, A., Thammapalo, S., Morrison, A.C., Libraty, D.H., Green, S. and Scott, T.W. (2008) Spatial and Temporal Clustering of Dengue Virus Transmission in Thai Villages. PLoS Medicine, 5, e205. http://dx.doi.org/10.1371/journal.pmed.0050205 


\section{Submit or recommend next manuscript to SCIRP and we will provide best service for you:}

Accepting pre-submission inquiries through Email, Facebook, LinkedIn, Twitter, etc.

A wide selection of journals (inclusive of 9 subjects, more than 200 journals)

Providing 24-hour high-quality service

User-friendly online submission system

Fair and swift peer-review system

Efficient typesetting and proofreading procedure

Display of the result of downloads and visits, as well as the number of cited articles

Maximum dissemination of your research work

Submit your manuscript at: http://papersubmission.scirp.org/ 